\title{
Coordination of Health Behavior Counseling in Primary Care
}

Deborab J. Coben, $P b D^{1}$

Bijal A. Balasubramanian, MBBS, $\mathrm{PbD}{ }^{2}$

Nicole F. Isaacson, $\mathrm{PbD}, \mathrm{MSF}^{3}$

Elizabeth C. Clark, MD, MPH

Rebecca S. Etz, $P b D^{3}$

Benjamin F. Crabtree, $\mathrm{PbD}^{3,4}$

'Department of Family Medicine, Oregon Health \& Sciences University, Portland, Oregon

${ }^{2}$ Division of Epidemiology, Human Genetics, and Environmental Sciences, University of Texas School of Public Health, Dallas, Texas

${ }^{3}$ Department of Family Medicine and Community Health, Robert Wood Johnson Medical School, University of Medicine \& Dentistry of New Jersey, Somerset, New Jersey

${ }^{4}$ Department of Epidemiology, School of Public Health, University of Medicine \& Dentistry of New Jersey, New Brunswick, New Jersey

Conflicts of interest: authors report none.

\section{CORRESPONDING AUTHOR}

Deborah J. Cohen, PhD

Department of Family Medicine Oregon Health \& Sciences University 3181 SW Sam Jackson Park Road Mail Code: FM

Portland, OR 97239

cohendj@ohsu.edu

\begin{abstract}
PURPOSE We wanted to examine how coordinated care is implemented in primary care practices to address patients' health behavior change needs.

METHODS Site visit notes, documents, interviews, and online implementation diaries were collected from July 2005 to September 2007 from practice-based research networks (PBRNs) participating in Prescription for Health: Promoting Healthy Behaviors in Primary Care Research Networks (P4H). An iterative group process was used to conduct a cross-case comparative analysis of 9 interventions. Published patient outcomes reports from $\mathrm{P} 4 \mathrm{H}$ interventions were referenced to provide information on intervention effectiveness.
\end{abstract}

RESULTS In-practice health risk assessment (HRA) and brief counseling, coupled with referral and outreach to a valued and known counseling resource, emerged as the best way to consistently coordinate and encourage follow-through for health behavior counseling. Findings from published P4H outcomes suggest that this approach led to improvement in health behaviors. Automated prompts and decision support tools for HRA, brief counseling and referral, training in brief counseling strategies, and co-location of referral with outreach facilitated implementation. Interventions that attempted to minimize practice or clinician burden through telephone and Web-based counseling systems or by expanding the medical assistant role in coordination of health behavior counseling experienced difficulties in implementation and require more study to determine how to optimize integration in practices.

CONCLUSIONS Easy-to-use system-level solutions that have point-of-delivery reminders and decision support facilitate coordination of health behavior counseling for primary care patients. Infrastructure is needed if broader integration of health behavior counseling is to be achieved in primary care.

Ann Fam Med 2011;9:406-415. doi:10.1370/afm.1245.

\section{INTRODUCTION}

U nhealthy behavior accounts for a large percentage of premature death and disability. Poor diet, smoking, risky drinking, and lack of physical activity are associated with chronic diseases, such as heart disease, hypertension, and diabetes. ${ }^{1-9}$ These 4 unhealthy behaviors are highly prevalent among Americans, with most adults failing to meet recommendations, ${ }^{10,11}$ and approximately $58 \%$ having multiple health behavior risks. ${ }^{10}$

Current evidence suggests that moderate- to high-intensity counseling is effective in helping people engage in healthy behaviors. ${ }^{12-15}$ This evidence comes largely from randomized controlled trials that offer specialized, clinic-based support and reach only a small proportion of those at risk for poor health behaviors. By contrast, primary care offers an important opportunity to provide health behavior counseling to a great proportion of the US population. ${ }^{11,16-20}$ Most Americans visit a primary care clinician at least once a year, ${ }^{21}$ and approximately $87 \%$ of these patients have or are at risk for unhealthy behaviors. ${ }^{10}$ 
Although primary care practices reach many patients in need of health behavior counseling, lack of adequate reimbursement, ${ }^{22}$ limited clinician time, ${ }^{20}$ and lack of expertise ${ }^{23,24}$ are major barriers. Some have noted that despite these challenges primary care practices may be best suited to play a coordinating role that can include identifying patients with health behavior change needs, offering brief counseling or advice, and leveraging advice with a referral for more intensive counseling and support. ${ }^{24-26}$ These activities, where there is a referral but limited communication between clinicians and health behavior counselors, have been referred to as coordination in mental health research. ${ }^{27,28}$ Few researchers, however, have studied how to implement coordinated care effectively in primary care practice to address patients' health behavior change needs. ${ }^{29-32}$

In 2001, the Robert Wood Johnson Foundation (RWJF) funded the Addressing Multiple Behavior Risk Factors in Primary Care project to review evidence regarding multiple health behavior risks and their association with morbidity and mortality, to identify evidence-based strategies to address these risks among primary care patients, and to develop recommendations for research, practice, and policy. ${ }^{33}$ This project highlighted the high prevalence of multiple health behavior risks in the United States ${ }^{19,34}$ and concluded that research on multiple health behavior risks in primary care was sparse. Evidence from this project suggested more research was needed to develop interventions that are realistic for the primary care setting. ${ }^{18}$

Conceived as an outcome of this work, Prescription for Health: Promoting Healthy Behaviors in Primary Care Research Networks ( $\mathrm{P} 4 \mathrm{H})$ was funded by the RWJF in collaboration with the Agency for Healthcare Research and Quality. P4H grantees developed and tested practical innovations for implementing health behavior counseling in primary care practices to address 4 health behavior risks-poor diet, physical inactivity, smoking, and risky drinking. There were 2 rounds of funding. This report focuses on round 2 (July 2005 to June 2007).

Applicants were practice-based research networks (PBRNs). PBRNs submitted proposals for implementing innovative interventions to improve the delivery of health behavior counseling in primary care practices. Applicants were strongly encouraged to use the 5As framework (ask, advise, assess, assist, arrange) $)^{15}$ and the Chronic Care Model (CCM) ${ }^{34}$ as theoretical frameworks for their interventions, and to use the RE-AIM framework (http://www.re-aim.org) to evaluate them. ${ }^{35,36}$ In addition, the RWJF National Program Office (NPO) coordinated the collection of a common set of patient outcome measures that assessed change in patients' health behaviors across funded PBRNs. ${ }^{37}$ Using these measures and others, 5 PBRNs reported the effect of $\mathrm{P} 4 \mathrm{H}$ interventions on patients' health behaviors. ${ }^{38-42}$ None reported on how coordination of health behavior counseling was implemented or made a part of practices' everyday routines, however. To translate evidence-based interventions into real-world primary care practice, it is imperative to understand and report on the implementation process. We therefore conducted a cross-PBRN comparative analysis of the $\mathrm{P} 4 \mathrm{H}$ interventions to examine the barriers and facilitators to implementing the care coordination process.

\section{METHODS}

The University of Medicine and Dentistry of New Jersey-Robert Wood Johnson Medical School (UMDNJRWJMS) Institutional Review Board approved the study protocol.

Ten PBRNs across the United States were funded as part of the $\mathrm{P} 4 \mathrm{H}$ program, and an independent evaluation was funded to observe the implementation process across projects. One PBRN was excluded from these analyses because of insufficient data, leaving 9 programs available for evaluation.

\section{Data Collection}

A multimethod evaluation was conducted to understand the barriers and facilitators experienced during implementation, and to draw out cross-PBRN lessons with regard to implementing health behavior counseling in primary care. Table 1 describes the types of data we collected for this evaluation. ATLAS.ti (version 5.2) was used for data management and analysis. PBRNs assigned their participating practices a unique numeric identifier that was used in our database. All data was deidentified and saved on a password-protected network maintained by UMDNJ-RWJMS. Published reports on changes in patients' health behaviors were obtained from principal investigators of the projects. ${ }^{38,40-42}$

\section{Analysis}

The evaluation team conducted a real-time analysis that involved reading and reflecting on data as they were collected. ${ }^{44,45}$ Data were discussed in weekly research meetings to understand implementation experiences; how practice and research teams responded as interventions were integrated into practice routines. An immersion-crystallization approach ${ }^{43-45}$ was used to examine data. First, the evaluation team analyzed data from each PBRN individually to identify all potential intervention elements of the health behavior counseling process. Using a grounded approach to analysis, 3 elements emerged as important: (1) screening for 
health behavior risk, (2) brief health behavior counseling, and (3) referral and link to external resources. Second, the team studied these elements across PBRNs to understand how each element was accomplished, and to identify barriers to and facilitators of implementation by reexamining relevant tagged text by clusters of code (eg, screening, intake, health risk assessment

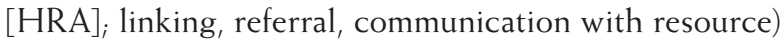

\begin{tabular}{|c|c|c|}
\hline $\begin{array}{l}\text { Primary } \\
\text { Data Type }\end{array}$ & Description of Data & Data Collection Process \\
\hline Documents & $\begin{array}{l}\text { Documents collected included: call for proposals } \\
\text { (CFPs), frequently asked questions (FAQs) and other } \\
\text { materials posted to the prescriptionforhealth.org } \\
\text { Web site; notes from NPO-sponsored meetings and } \\
\text { e-mail communications when available; grant appli- } \\
\text { cations and grantee reports; manuscripts, training } \\
\text { materials, grantee presentations }\end{array}$ & $\begin{array}{l}\text { Documents were collected throughout the study period from the } \\
\text { Web site; the NPO and grantees shared documents freely }\end{array}$ \\
\hline \multirow[t]{6}{*}{$\begin{array}{l}\text { Online } \\
\text { diaries }^{43}\end{array}$} & \multirow{6}{*}{$\begin{array}{l}\text { The online diaries produced written documentation } \\
\text { of what was observed and experienced during } \\
\text { implementation of each intervention. Several hun- } \\
\text { dred pages of rich description of implementation } \\
\text { processes were documented across PBRNs using the } \\
\text { online diaries }\end{array}$} & $\begin{array}{l}\text { Research teams helped to identify persons who were working closely } \\
\text { with practices and who could write about their observations and } \\
\text { experiences during implementation }\end{array}$ \\
\hline & & $\begin{array}{l}\text { The study principal investigator and } 4 \text { to } 6 \text { team members were } \\
\text { identified from each team }\end{array}$ \\
\hline & & $\begin{array}{l}\text { Each funded PBRN had a private diary room to which only the diary } \\
\text { keepers and the evaluators had access }\end{array}$ \\
\hline & & $\begin{array}{l}\text { Diary keepers posted entries approximate every } 2 \text { weeks; entries were } \\
\text { viewed and responded to by other diary keepers from the team }\end{array}$ \\
\hline & & $\begin{array}{l}\text { Evaluator also interacted with diary keepers in real time, asking } \\
\text { questions and discussing and responding to diary entries }\end{array}$ \\
\hline & & Diary data were collected throughout the study period \\
\hline Site visits & $\begin{array}{l}\text { Members of the NPO and evaluation team conducted } \\
\text { 2-day visits to each PBRN. Field notes were prepared } \\
\text { by the evaluators on the site visit to document } \\
\text { observations about the PBRN, the intervention, and } \\
\text { the practices they visited. The NPO generated a site } \\
\text { visit report that is also included in our data }\end{array}$ & $\begin{array}{l}\text { Site visits to } 2 \text { practices participating in each PBRN were conducted } \\
\text { after implementation. Evaluators spoke with PBRN team members } \\
\text { and with key informants. When possible, evaluators observed prac- } \\
\text { tice members doing the intervention }\end{array}$ \\
\hline Interviews & $\begin{array}{l}\text { Group interviews were conducted with grantees at } \\
\text { NPO-sponsored meetings. Field notes were prepared } \\
\text { to capture what was said during these interviews }\end{array}$ & $\begin{array}{l}\text { Interviews were conducted once a year: at baseline, } 1 \text { year into the } \\
\text { study, and at the conclusion of the study. If needed, telephone } \\
\text { interviews were scheduled to address unanswered questions about } \\
\text { an intervention }\end{array}$ \\
\hline Surveys & $\begin{array}{l}\text { A Web-based, practice questionnaire was collected } \\
\text { from each participating practice to assess practice } \\
\text { demographic information (eg, practice size, owner- } \\
\text { ship, staffing, payer mix, patient panel) }\end{array}$ & $\begin{array}{l}\text { Practice survey data were collected at baseline (preintervention). One } \\
\text { person per practice (eg, office manager, lead physician) completed } \\
\text { the questionnaire, with grantees assisting as needed. Grantees col- } \\
\text { lected and returned questionnaires to the evaluators }\end{array}$ \\
\hline
\end{tabular}

Table 2. Characteristics of Practice-Based Research Networks and Practices in Prescription for Health

\begin{tabular}{|c|c|c|c|c|c|c|}
\hline Characteristic & PBRN 1 & PBRN 2 & PBRN 3 & PBRN 4 & PBRN 5 & PBRN 6 \\
\hline PBRN study design & $\begin{array}{l}\text { Quasi-experimental } \\
\text { (patient level) }\end{array}$ & $\begin{array}{l}\text { Quasi-experimental } \\
\text { (practice level) }\end{array}$ & Pre-post & $\begin{array}{l}\text { Quasi-experimental } \\
\text { (patient level) }\end{array}$ & Pre-post & Pre-post \\
\hline $\begin{array}{l}\text { Study comparison } \\
\text { group }\end{array}$ & Usual care & Usual care & None & Usual care & None & None \\
\hline Practices in networks, $\mathrm{n}$ & 9 & 6 & 15 & 7 & 9 & 6 \\
\hline \multicolumn{7}{|l|}{ Practice type, n } \\
\hline Solo & 2 & 0 & 2 & 2 & 8 & 2 \\
\hline Single specialty & 6 & 0 & 7 & 4 & 0 & 4 \\
\hline Multispecialty & 1 & 6 & 6 & 1 & 1 & 0 \\
\hline \multicolumn{7}{|l|}{ Practice ownership, $n$} \\
\hline Clinician & 0 & 0 & 3 & 2 & 8 & 3 \\
\hline Hospital health system & 9 & 5 & 6 & 4 & 0 & 1 \\
\hline University health system & 0 & 1 & 0 & 0 & 0 & 1 \\
\hline Other & 0 & 0 & 6 & 1 & 1 & 1 \\
\hline Clinician FTE, mean (SD), $n$ & $2.8(1.8)$ & $4.3(1.4)$ & $3.9(3.3)$ & $3.5(2.2)$ & $1.1(0.3)$ & $3.5(2.1)$ \\
\hline
\end{tabular}

FTE = full-time equivalent; PBRN = practice-based research network. 
across PBRNs. We created an analysis table to identify key tasks and to track, by PBRN, how tasks were accomplished and the presence and absence of barriers to and facilitators of implementation. We then used this table to seek out confirming and disconfirming cases. We further refined our findings through additional analysis of these cases.

\section{RESULTS}

The 9 funded PBRNs participating in the study comprised a broad range of practices that varied with regard to practice type, ownership, and size (Table 2). They used a variety of study designs (quasi-experimental, pre-post, randomized controlled trial) to test the effectiveness of their interventions. The PBRNs implemented interventions that included patient screening, counseling, and referral to more intensive counseling (Table 3). Two PBRNs targeted children and adolescents, and 4 reached a sample of African American and Hispanic patients (Table 4). Additionally, PBRNs and the NPO reported that 6 of the $\mathrm{P} 4 \mathrm{H}$ interventions led to improvements in patient health behaviors, predominantly improvements in diet (Table 4).

We considered these reports of the effectiveness of $\mathrm{P} 4 \mathrm{H}$ interventions in improving patient behaviors as we compared how the interventions were implemented - made a part of the everyday routines - in real-world primary care practices and the factors that facilitated and inhibited the implementation of the coordination process.

Systematic Screening for Health Behavior Risk All interventions included some method of screening for health behavior risk. Six PBRNs developed methods

PBRN 7

Patient-randomized intervention usual care 6 0
3 3 0

0 5

1

$8.0(3.5)$
PBRN 8

Patient-randomized intervention Web-based information

6

\section{0}

5

1

0

3

2

1

$7.8(8.4)$
PBRN 9

Patient-randomized intervention

Paper education materials

8

3

4

1

3

3

2

0

$3.3(3.1)$

ANNALS OF FAMILY MEDICINE + WWW.ANNFAMMED.ORG + VOL. 9, NO. 5 + SEPTEMBER/OCTOBER 2011

for screening patients within the practice, and 3 PBRNs conducted screening outside the practice.

\section{In-Practice Screening}

For in-practice screening, practices used either information technology (IT)- or paper-based tools to administer HRAs to patients. Implementation was facilitated when practices were able to integrate screening into existing care processes and screening tools matched the needs of the patient population. One way to fit screening into existing care processes was through computer automation. PBRN 1 modified an existing electronic health record (EHR) to prompt the HRA as part of the routine rooming process, and staff members reported that they perceived this change incurred no additional work or time. In addition, one physician stated that it "helps him notice behaviors that might otherwise have gone off the radar" (site visit notes, PBRN 1). ${ }^{46}$ By contrast, without effective reminders or integration into routine processes, practice staff in other participating PBRN practices struggled to implement screening consistently:

... she said that it has been difficult to institute the health risk assessment simply because the staff members are reluctant to add a new step to their already busy routines. The front desk staff often forgets to hand out the survey to patients as they check in (diary entry, PBRN 2).

Two PBRNs (PBRNs 5 and 7) attempted to keep the intervention on staff members' minds by placing posters on office walls and developing motivational slogans. These efforts were largely ineffective, however, because they did not require staff to screen patients before they could move on to other activities.

Implementation of systematic screening was also aided when screening tools matched the intended targeted patient population. For example, PBRN 4 developed an HRA that adolescents completed by using a personal digital assistant (PDA). The strong match of this tool with the patient population facilitated health behavior discussions.

One mother commented...that when her older son had been in and completed the PDA, he liked the visit much better "because the doctor didn't stare at me and ask me questions." That story prompted similar comments from [clinicians] (diary entry, PBRN 4).

Screening tools that were not well matched to the patient population hindered implementation. A Web tablet HRA in PBRN 6 was difficult for older patients to read, and office staff reported choosing not to screen this patient group as a result. In other projects, some patients were intimidated by the HRA or lacked 


\section{Table 3. Description of Prescription for Health Interventions}

\begin{tabular}{ll}
\hline PBRN & Description \\
\hline PBRN 1 & Study tested whether 5As intervention using EHR improved unhealthy behav- \\
iors in primary care patients, compared with usual care. EHR prompted \\
rooming staff to ask about and record health risk; EHR identified patient risk \\
and, when risk was present, prompted clinicians to consider brief counseling; \\
if clinician chose to counsel patients, the EHR prompted the clinician through \\
a 5As-based brief counseling process that gave clinicians the ability to click to \\
refer patients to 1 of 4 external counseling options: Web-based counseling, \\
telephone counseling, group counseling, usual care. Patients selecting tele- \\
phone or group counseling were called by resource within 24 hours to set up \\
counseling sessions. Participating practices = 9, within a single health system \\
using the same EHR
\end{tabular}

PBRN $2 \quad$ Study tested preventing unhealthy diet/activity behaviors by targeting 2-yearold well-child visit with new goal-setting tool and referral to a health educator, as compared with usual care. Patients completed HRA in waiting room before 2-year-old well-child visits using paper-based protocol with assistance from staff, as needed; HRA triggered clinician to provide brief counseling and goal-setting and referral to health educator provided by study; health educator called patients to schedule a counseling visit and then referred to available resources when needed. Participating practices $=6$

PBRN 3 Study tested the effect of having a health educator/community liaison available to practices. Practices identified at-risk patients; referred patients to health educator/community liaison, who conducted a HRA, provided counseling and follow-up, and assisted in connecting patients to community resources. Participating practices $=15$, located in 3 disparate geographic areas

PBRN 4 Study tested use of PDA-based comprehensive health screener as a catalyst to enhance counseling, communication, referrals, and follow-up related to behavior change in adolescents, as compared with usual care. Adolescent patients conducted self-HRA using PDA in waiting room; results reviewed before the examination; clinicians offered brief counseling and provided resource card and referrals as needed. Participating practices $=8$

PBRN 5 Study tested impact of performance feedback, training, practice facilitation, and local QI collaboratives on health behavior change efforts in primary care. Study provided monthly performance audits, training for each behavior and for motivational interviewing; study facilitated plan-do-study-act cycles to add screening of behaviors, one by one, cumulatively, as part of vital signs process; patients given printed handouts and referrals as appropriate; regional area practices shared performance data and lessons learned. Participating practices $=9$

PBRN 6 Study promoted screening, counseling, and community resource use through collaboration with local health department using extension agent model. Patients conducted IT-based self-HRA and readiness to change assessment in the waiting room; the HRA was printed and triggered brief counseling and referral to extension resources and other existing resources by clinician. Participating practices $=6$

PBRN $7 \quad$ Study tested MA-led program designed to identify patients at risk for poor health behaviors, who were offered counseling and referral to community resource, as compared with usual care. MAs reviewed recent electronic-based patient HRAs and assessed patient readiness to change, offered brief counseling and referral for ready patients at risk for behaviors covered by written protocol, and alerted clinicians to patients at risk and ready to change but who were outside the MA protocol. Participating practices $=6$

PBRN $8 \quad$ Study tested patient use of provision of Web-based tools to assist patients with health behaviors, as compared with usual care. Letters issued to patients identified by practice mailing list. Letters prompted patients to conduct selfHRA via Web site; patients received feedback, at-risk patients encouraged to participate in Web-based counseling; system could update clinician on patient progress. Participating practices $=6$

PBRN 9 Study tested integration of proven interactive telephone voice response system into primary care practices to promote behavior change, as compared with provision of educational materials only. Clinicians or practice staff identified appropriate patients, provided educational materials and brief counseling message, and referred to telephone counseling system. Patients were to call the system; HRA conducted by the system on first call. Patients determined to be at risk for poor health behaviors were encouraged by the telephone system to call in weekly for counseling. Participating practices $=8$

$5 \mathrm{As}=$ ask, advise, assess, assist, arrange; $\mathrm{EHR}=$ electronic health record; HRA = health risk assessment: $\mathrm{IT}=$ information technology; $\mathrm{MA}=$ medical assistant; PDA = personal digital assistant; $\mathrm{QI}=$ quality improvement. the literacy skills or information to complete it.

\section{Out-of-Practice Screening}

In an attempt to minimize the burden on the practice, 3 PBRNs chose to have the HRA completed outside the practice. For example, in 2 of these studies (PBRNs 8 and 9), external ITbased tools (ie, Web-based and automated telephone systems) screened referred patients for health risk. These interventions experienced poor or inconsistent patient referral and lack of patient uptake. In PBRN 9, practices handed out an information packet, and patients were instructed to contact a telephone counseling system. Few patients initiated contact with the telephone system, requiring the research team to become involved:

When patients don't initiate the system after 10 days, I will call and set up the system with their contact information.... If they don't complete the HRA within 2 weeks,... I will send them a paper HRA survey and ask them to complete and return the document to me along with a reminder that they can complete the survey over the telephone (diary entry, PBRN 9).

\section{Practice-Based Brief Health Behavior Counseling}

Seven PBRNs implemented some form of brief health behavior counseling in the practice. Implementation was facilitated when interventions included EHR-based counseling prompts, paper-based goal-setting forms, or learning opportunities in brief counseling approaches. For example, in PBRN 4 clinicians were trained in motivational interviewing techniques. ${ }^{41}$ Clinicians in these practices were already accustomed to briefly counseling patients, and training enhanced existing processes and skills (site visit notes, PBRN 4). 
In contrast, implementation of brief counseling was hindered when counseling responsibilities did not match practice members' role and skills. In PBRN 7, medical assistants were responsible for most brief counseling. This role was a major change for most medical assistants, ${ }^{38}$ and 3 barriers to implementation emerged. First, medical assistants did not feel adequately trained to briefly counsel patients:

I find it hard to preach about losing weight when I'm sitting there and I'm 80 pounds overweight... Now, smoking... I talk them into going to that smoke cessation class all the time, and I tell them, "I can say this because I used to smoke, so I know where you're at" (interview, PBRN 7).

Second, medical assistants often perceived that patients did not trust or value their health behavior advice. As one medical assistant reported: "They don't think we know a lot or we can't do a lot for them." Third, medical assistants felt that clinicians frequently did not support them in this new role:

A lot of the doctors...say, "You don't have to do it. Don't do it." Because a lot of the doctors, you know, want to get their patients in and out...so they don't get behind (interview, PBRN 7).

\section{Referral and Link to Health Behavior Counseling Resources}

\section{Referral and Link}

Two types of referral processes were tested in $\mathrm{P} 4 \mathrm{H}$ : (1) traditional referrals, in which patients receive a referral and make contact with the resource; and (2) referral with outreach, in which patients receive a referral and the resource initiates contact with patients. PBRNs that used a referral with outreach approach were more likely to have patients engage in intensive counseling. For example in PBRN 1, 75\% of the referred patients followed through with intensive counseling. ${ }^{46}$ Less is known about links between patients and resources using the traditional referral process, because followthrough on referral was not assessed by PBRNs. When patients were given traditional referrals to automated telephone- and Web-based counseling systems, however, they often failed to initiate contact. For example, PBRN 8 relied on mass mailings to refer and link patients to a Web-based counseling tool. This PBRN sent out 7,706 letters to patients at 6 practices, and 169 patients $(2 \%)$ used the Web site, leading the PBRN to modify its approach:

Realizing that response to mailing is going to be limited, we have sought ways to increase interest in the project at the doctor's office.... We think that having a clinician talk to the patient about trying the site is a good way to get people to come (diary entry, PBRN 8).
As we show above, PBRN 9 handed out information about the telephone counseling system and also struggled to get patients to initiate contacting this resource after a referral.

Locating an intensive health behavior counseling resource in the practice (co-location) ${ }^{28}$ helped the referral process. Even so, only 1 PBRN (PBRN 2) in $\mathrm{P} 4 \mathrm{H}$ deliberately had this design. ${ }^{47}$ In another project, co-location emerged unexpectedly and provided insight as to its value:

The closer the [health behavior counselor] can be to the practice, the more effectively she can be accessed by the practice to serve the patients' needs. Also, the closer association with the doctors often makes patients even more receptive to her advice and intervention. In many ways, having the [health behavior counselor] located IN the practice is ideal-she knows the providers, is familiar with the patients, can respond to immediate questions and issues, can provide even more immediate feedback to integrate her care with the team (diary entry, PBRN 3).

\section{Characteristics of External Health Behavior Counseling Resources}

Certain characteristics of the external counseling resources shaped the referral process. Resources that were unfamiliar to patients and clinicians could make the referral process more difficult because resources required explanation, and patients had more questions that physicians were often not well equipped to answer. Resources that were well known to and valued by patients (eg, Weight Watchers) facilitated the referral process. The cost of health behavior counseling resources was also important. In PBRN 1, when counseling resources changed from being free to charging a fee, the referral process became more difficult; physicians did not bring up counseling as often because patients were reluctant to pay for counseling services. ${ }^{46}$ Finally, the location of these services, as shown above, could strengthen the connection and communication among patient, clinician, and health behavior counselor.

\section{DISCUSSION}

The $\mathrm{P} 4 \mathrm{H}$ program offered an important opportunity to examine how health behavior counseling can be coordinated in primary care. Our findings show that the combination of in-practice HRA and brief counseling, coupled with referral and outreach to a valued and known counseling resource, can be implemented in practices. In addition, in $\mathrm{P} 4 \mathrm{H}$ this method emerged as the best way to consistently screen patients, briefly counsel them, and encourage follow-through to counseling resources. Findings from published $\mathrm{P} 4 \mathrm{H}$ analyses 


\section{Table 4. Patient Characteristics and Effects of Prescription for Health Interventions on Patients' Health Behaviors}

\begin{tabular}{|c|c|c|c|c|c|}
\hline \multirow[b]{2}{*}{ Characteristics } & \multirow[b]{2}{*}{$\begin{array}{c}\text { PBRN } 1 \\
(n=9)\end{array}$} & \multirow[b]{2}{*}{$\begin{array}{c}\text { PBRN } 2 \\
(n=6)\end{array}$} & \multicolumn{3}{|c|}{$\begin{array}{c}\text { Practice-Based Research Network } \\
\text { (No. of Practices in Network) }\end{array}$} \\
\hline & & & $\begin{array}{l}\text { PBRN } 3 \\
(n=15)\end{array}$ & $\begin{array}{l}\text { PBRN } 4 \\
(n=7)\end{array}$ & $\begin{array}{c}\text { PBRN } 5 \\
(n=9)\end{array}$ \\
\hline \multicolumn{6}{|l|}{ Patients } \\
\hline Patient eligibility & $\begin{array}{l}\text { Adult patients pre- } \\
\text { senting to practice }\end{array}$ & $\begin{array}{l}\text { Children } 2-5 \text { y for } \\
\text { well-child care }\end{array}$ & $\begin{array}{l}\text { Adult patients, } \\
\text { practice tailored }\end{array}$ & Teen health visits & $\begin{array}{l}\text { Practice } \\
\text { tailored }\end{array}$ \\
\hline Referred, No. & 407 & 354 & 797 & 148 & 1,442 \\
\hline Age, median, y & 57 & 3 & 50 & 15 & 52 \\
\hline Female. \% & 66 & 50 & 30 & 50 & 31 \\
\hline African American, \% & 26 & 27 & 18 & NA & 9 \\
\hline Hispanic, \% & 3 & 72.8 & 3 & 3.5 & 3 \\
\hline Household income $<\$ 25,000, \%^{\text {a }}$ & - & - & 41 & - & 41 \\
\hline At least high school education, \%a & 38 & - & 39 & - & 40 \\
\hline $\begin{array}{l}\text { Reported significant improvements in } \\
\text { patient behaviors }\end{array}$ & Yes: F/V, BMI, PA ${ }^{44}$ & $\begin{array}{c}\text { No: all } \\
\text { behaviors }\end{array}$ & $\begin{array}{l}\text { Yes: PA, F/V, } \\
\text { RD, S, D } 42\end{array}$ & $\begin{array}{l}\text { Yes: PA; milk } \\
\text { consumption }{ }^{43}\end{array}$ & $\begin{array}{c}\text { No: all } \\
\text { behaviors }\end{array}$ \\
\hline
\end{tabular}

suggest that this approach also can lead to improvement in patient health behaviors, ${ }^{42,46}$ with a number of interventions reporting improvements in patient outcomes. ${ }^{40,41,48}$ Translating interventions into primary care requires tailoring to fit the unique characteristics of practices, ${ }^{49}$ and discussion of the nuances among the $\mathrm{P} 4 \mathrm{H}$ interventions will help practice leaders and other health care decision makers identify the trade-offs involved when attempting translation.

One important consideration is how patients are screened for risky behaviors. Consistent screening can lead to more consistent brief clinician counseling and referral. As our results show, PBRN 1 had excellent follow-through on referral because the EHR automatically prompted the rooming staff to ask about and record HRAs, and then prompted clinicians to use the $5 \mathrm{As}^{15}$ to counsel and assess patient readiness to change. ${ }^{46}$ As a result of the screening and counseling process, clinicians identified and referred their most motivated patients. This PBRN and others also show that using IT tools to automate in-practice HRAs can lead to consistent identification, counseling, and referral of patients at risk for unhealthy behaviors. ${ }^{41,46}$ Expertise, however, is needed to develop and implement IT-based HRA and brief counseling tools in practice. As other $\mathrm{P} 4 \mathrm{H}$ reports have shown, practices typically do not have these resources. ${ }^{49}$ Paperbased tools can be less expensive, easier to create, and appealing to patients, ${ }^{47}$ but work must be done to make paper-based tools part of the patient care routine so this information is consistently collected, evaluated, and discussed.
A second important consideration is how referrals are made to external counseling resources. We observed 2 approaches for making referrals: traditional referral and referral with outreach. In addition, $\mathrm{P} 4 \mathrm{H}$ interventions allowed us to observe how the location of the counseling resource influenced the referral process. What we found is that co-located services and referral with outreach foster a warmer patient hand-off between the clinician and counselor that may enhance coordination and patient follow-through. ${ }^{40,46,47}$ It is important to recognize that adequate patient volume and reimbursement are necessary to support these activities financially, and the costs and benefits of these approaches require further assessment. Our findings show that future research to examine the effectiveness of various referral approaches must be examined in the context of the screening and counseling processes used by practices. The manner in which practices screen and assess patients' readiness for change can influence the effectiveness of subsequent referral and intensive counseling.

Cost of health behavior counseling services is another consideration. Although most of the counseling resources that patients received were free (ie, paid by grant funds or available in the community), change in out-of-pocket costs could dull patients' enthusiasm and, in turn, reduce the extent to which practices screen, counsel, and offer referrals to patients. ${ }^{46}$ More research is needed to understand what patients value and are willing to pay for with regard to health behavior counseling and to explore what community stakeholders (ie, insurers, large employers) may be willing to pay to incentivize health behavior change. 


\begin{tabular}{|c|c|c|c|}
\hline $\begin{array}{c}\text { PBRN } 6 \\
(n=6)\end{array}$ & $\begin{array}{c}\text { PBRN } 7 \\
(n=6)\end{array}$ & $\begin{array}{c}\text { PBRN } 8 \\
(n=6)\end{array}$ & $\begin{array}{l}\text { PBRN } 9 \\
(n=8)\end{array}$ \\
\hline $\begin{array}{l}\text { Practice } \\
\text { tailored }\end{array}$ & $\begin{array}{l}\text { Adult patients } \\
\text { MA discretion }\end{array}$ & $\begin{array}{l}\text { Adult patients pre- } \\
\text { senting to practice }\end{array}$ & $\begin{array}{l}\text { Adult patients, } \\
\text { practice tailored }\end{array}$ \\
\hline 245 & 437 & 169 & 215 \\
\hline 44 & 46 & 51 & 5 \\
\hline 23 & 74 & 21 & 28 \\
\hline 40 & 7 & 3 & 8 \\
\hline 4 & 69 & 10 & .6 \\
\hline 38 & 92 & 17 & 32 \\
\hline 42 & 66 & 7 & 36 \\
\hline Yes: RD² & $\begin{array}{c}\text { No: all } \\
\text { behaviors }\end{array}$ & Yes: $D^{41 b}$ & Yes: $D^{41}$ \\
\hline
\end{tabular}

Finally, we observed important trade-offs when trying to minimize cost and clinician and practice burden in the delivery of health behavior counseling to primary care patients. One way to minimize clinician burden that was tested in $\mathrm{P} 4 \mathrm{H}$ was the expansion of the medical assistant role to include coordination of health behavior counseling. This effort has the important benefit of promoting a team-based approach to care and potentially freeing up clinicians for reimbursed activities. Although the effect of this intervention on patient outcomes is unclear, further testing to identify how best to expand the medical assistant's role in primary care is warranted. ${ }^{38,48}$

A second way to minimize cost and burden that was tested in $\mathrm{P} 4 \mathrm{H}$ was telephone- and Web-based health behavior counseling systems. These systems were difficult to implement in practices, in part because implementation may have been narrowly defined as giving patients information about the system. It is less clear how clinicians counseled patients and recommended using these systems. We know that these interventions reached fewer patients, and PBRNs struggled with patient uptake. It is, however, important to note the potential benefits of automated counseling systems. Telephone and Web-based counseling systems can be available to an unlimited number of practices and patients and are of low cost. These systems can be available in resource-poor communities, and the nature and intensity of the counseling can be controlled. Although $\mathrm{P} 4 \mathrm{H}$ interventions showed that these systems led to health behavior change for the few patients who used them, ${ }^{39}$ more research is needed to better understand how to make these systems more appealing to a wider range of patients, and how to make primary care one platform, perhaps among many, for socially marketing automated counseling systems to patients.

This study's findings must be considered in the context of some limitations. As external evaluators to the $\mathrm{P} 4 \mathrm{H}$ program, we relied on key informants working closely with practices during implementation to share their experiences. We used multiple methods (online diaries, interviews, site visits) to support thorough data collection. Variability remained in grantees' participation in the evaluation, however. This limitation was mitigated in a number of ways. First, participation in evaluation was a condition of funding. Second, throughout the program the value and usefulness of evaluation data were shown to grantees. Third, insights from the data and the data itself were shared with grantees in real time. This step rewarded grantees for their effort with data collection.

Another limitation of our work concerns the comparability of patient outcome data. Even though the NPO coordinated the collection of patient outcome data using a set of common measures ${ }^{37}$ they did not dictate what study designs grantees should use, how and at what intervals these data should be collected, and whether a comparison group should be used. As a result, there was wide variation in study designs across PBRNs that made it difficult to align patient outcomes with implementation findings. Even so, we were able to obtain peer-reviewed patient outcomes for many of the studies that were performed by the investigators at the PBRNs.

Despite these limitations, the findings of this study show that health behavior counseling can be implemented in the primary care setting through care coordination. Our comparative analysis of the $\mathrm{P} 4 \mathrm{H}$ interventions identifies factors that greatly facilitate health behavior counseling in primary care and that also correlate with improvements in patient behaviors. This research can inform practice redesign efforts, funding, and reimbursement decisions.

To read or post commentaries in response to this article, see it online at http://www.annfammed.org/cgi/content/full/9/5/406.

Key words: Health behavior; health promotion; quality improvement; patient-centered care; delivery of health care; delivery of health care; health services research; outcomes and process assessment (health care); program evaluation

Submitted June 16, 2010; submitted, revised, December 17, 2010; accepted January 6, 2011.

Funding support: This work was supported by grant No. 053221 from the Robert Wood Johnson Foundation. 
Prior presentations of variations of the work are reported as follows:

Cohen, DJ, Balasubramanian, BA, and Isaacson, N. Translating behavioral interventions into primary care practice. Presented at the Society of Behavior Medicine Meeting, Montreal, Canada, April 22-25, 2009. SBM 2009 Proceedings.

Clark, EC, Cohen, DJ, Balasubramanian, BA, Isaacson, NF, Etz, RS, Crabtree, BF. Translating behavioral interventions into primary care practice. Poster presented at the American College of Preventive Medicine Meeting, Los Angeles, Feb 11-14, 2009.

Cohen, DJ, Balasubramanian, BA, Isaacson, NF, Etz, RS, Clark, EC. Translating behavioral interventions into primary care practice. Poster \#323 presented at the Academy Health Meeting, Chicago, Jun 27-30, 2009.

\section{References}

1. Eaton DK, Kann L, Kinchen S, et al. Youth risk behavior surveillance-United States, 2005. MMWR Surveill Summ. 2006;55(5):1-108.

2. Ford ES, Ajani UA, Croft JB, et al. Explaining the decrease in U.S. deaths from coronary disease, 1980-2000. N Engl J Med. 2007;356 (23):2388-2398

3. McGinnis JM, Foege WH. Actual causes of death in the United States. JAMA. 1993;270(18):2207-2212.

4. Mokdad AH, Marks JS, Stroup DF, Gerberding JL. Actual causes of death in the United States, 2000. JAMA. 2004;291(10)1238-1245.

5. Ogden CL, Carroll MD, Curtin LR, McDowell MA, Tabak CJ, Flegal KM. Prevalence of overweight and obesity in the United States, 1999-2004. JAMA. 2006;295(13):1549-1555.

6. Ogden CL, Flegal KM, Carroll MD, Johnson CL. Prevalence and trends in overweight among US children and adolescents, 1999 2000. JAMA. 2002;288(14):1728-1732.

7. Seffrin JR. An end-game for cancer. CA Cancer J Clin. 2000;50(1):4-5.

8. Troiano RP, Flegal KM. Overweight children and adolescents: description, epidemiology, and demographics. Pediatrics. 1998; 101(3 Pt 2):497-504.

9. Yusuf S, Hawken S, Ounpuu S, et al; INTERHEART Study Investigators. Effect of potentially modifiable risk factors associated with myocardial infarction in 52 countries (the INTERHEART study): casecontrol study. Lancet. 2004;364(9438):937-952.

10. Fine LJ, Philogene GS, Gramling R, Coups EJ, Sinha S. Prevalence of multiple chronic disease risk factors. 2001 National Health Interview Survey. Am J Prev Med. 2004;27(2)(Suppl):18-24.

11. Pronk NP, Anderson LH, Crain AL, et al. Meeting recommendations for multiple healthy lifestyle factors. Prevalence, clustering, and predictors among adolescent, adult, and senior health plan members. Am J Prev Med. 2004;27(2)(Suppl):25-33.

12. U.S. Preventive Services Task Force. Behavioral counseling in primary care to promote physical activity: recommendation and rationale. Ann Intern Med. 2002;137(3):205-207.

13. U.S. Preventive Services Task Force. Behavioral counseling in primary care to promote a healthy diet: recommendations and rationale. Am J Prev Med. 2003;24(1):93-100.

14. U.S. Preventive Services Task Force. Screening and behavioral counseling interventions in primary care to reduce alcohol misuse: recommendation statement. Ann Intern Med. 2004;140(7):554-556.

15. Whitlock EP, Orleans CT, Pender N, Allan J. Evaluating primary care behavioral counseling interventions: an evidence-based approach. Am J Prev Med. 2002;22(4):267-284.

16. Berrigan D, Dodd K, Troiano RP, Krebs-Smith SM, Barbash RB. Patterns of health behavior in U.S. adults. Prev Med. 2003;36(5):615-623.

17. Coups EJ, Gaba A, Orleans CT. Physician screening for multiple behavioral health risk factors. Am J Prev Med. 2004;27(2) (Suppl):34-41.
18. Goldstein MG, Whitlock EP, DePue J; Planning Committee of the Addressing Multiple Behavioral Risk Factors in Primary Care Project. Multiple behavioral risk factor interventions in primary care. Summary of research evidence. Am J Prev Med. 2004;27(2)(Suppl):61-79.

19. Pronk NP, Peek CJ, Goldstein MG. Addressing multiple behavioral risk factors in primary care. A synthesis of current knowledge and stakeholder dialogue sessions. Am J Prev Med. 2004;27(2)(Suppl): 4-17.

20. Yarnall KS, Pollak KI, Østbye T, Krause KM, Michener JL. Primary care: is there enough time for prevention? Am J Public Health. 2003; 93(4):635-641.

21. Green LA, Fryer GE Jr, Yawn BP, Lanier D, Dovey SM. The ecology of medical care revisited. N Engl J Med. 2001;344(26):2021-2025.

22. Rosen MA, Logsdon DN, Demak MM. Prevention and health promotion in primary care: baseline results on physicians from the INSURE Project on Lifecycle Preventive Health Services. Prev Med. 1984;13(5):535-548.

23. Bodenheimer T, Laing BY. The teamlet model of primary care. Ann Fam Med. 2007;5(5):457-461.

24. Stange KC, Woolf SH, Gjeltema K. One minute for prevention: the power of leveraging to fulfill the promise of health behavior counseling. Am J Prev Med. 2002;22(4):320-323.

25. Center for the Advancement of Health. Integration of Health Behavior Counseling in Routine Medical Care. Washington, DC: Center for the Advancement of Health; 2001.

26. Woolf $\mathrm{SH}$, Glasgow RE, Krist A, et al. Putting it together: finding success in behavior change through integration of services. Ann Fam Med. 2005;3(Suppl 2):S20-S27.

27. Blount A. Integrated primary care: Organizing the evidence. Fam Syst Health. 2003;21(2):121-133.

28. Miller BF, Mendenhall TJ, Malik AD. Integrated primary care: an inclusive three-world view through process metrics and empirical discrimination. J Clin Psychol Med Settings. 2009;16(1):21-30.

29. Butler M, Kane RL, McAlpin D. Integration of Mental Health/Substance Abuse and Primary Care (Prepared by the Minnesota Evidencebased Practice Center under Contract No. 290-02-009.). Rockville, MD: Agency for Healthcare Research and Quality; 2008.

30. Katon W, Unützer J. Collaborative care models for depression: time to move from evidence to practice. Arch Intern Med. 2006;166(21): 2304-2306.

31. Institue of Medicine. Committee on Crossing the Quality Chasm: Adaptation to Mental Health and Addictive Disorders. Washington, DC: National Academy of Sciences; 2006.

32. Craven M, Bland R. Better practices in collaborative mental health care: An analysis of the evidence base. Can J Psych. 2006;51 (6 Suppl 1):7S-72S.

33. Goldstein MG. Acknowledgement. Am J Prev Med. 2004;27 (2(Suppl 1)):iv.

34. Center for Policy Studies in Famkily Practice and Primary Care. The importance of having a usual source of health care [policy center one-pager]. Am Fam Physician. 2000;62(3):477.

35. Glasgow RE, Lichtenstein E, Marcus AC. Why don't we see more translation of health promotion research to practice? Rethinking the efficacy-to-effectiveness transition. Am J Public Health. 2003;93(8): 1261-1267.

36. Glasgow RE, Vogt TM, Boles SM. Evaluating the public health impact of health promotion interventions: the RE-AIM framework. Am J Public Health. 1999;89(9):1322-1327.

37. Glasgow RE, Ory MG, Klesges LM, Cifuentes M, Fernald DH, Green LA. Practical and relevant self-report measures of patient health behaviors for primary care research. Ann Fam Med. 2005;3(1):73-81.

38. Ferrer RL, Mody-Bailey P, Jaén CR, Gott S, Araujo S. A medical assistant-based program to promote healthy behaviors in primary care. Ann Fam Med. 2009;7(6):504-512. 
39. Fernald DH, Froshaug DB, Dickinson LM, et al. Common measures, better outcomes (COMBO): a field test of brief health behavior measures in primary care. Am J Prev Med. 2008;35(5)(Suppl):S414-S422.

40. Holtrop JS, Dosh SA, Torres T, Thum YM. The community health educator referral liaison (CHERL): a primary care practice role for promoting healthy behaviors. Am J Prev Med. 2008;35(5)(Suppl): S365-S372.

41. Olson AL, Gaffney CA, Lee PW, Starr P. Changing adolescent health behaviors: the healthy teens counseling approach. Am J Prev Med. 2008;35(5 Suppl):S359-S364.

42. Wilson DB, Johnson RE, Jones RM, Krist AH, Woolf SH, Flores SK. Patient weight counseling choices and outcomes following a primary care and community collaborative intervention. Patient Educ Couns. 2010;79(3):338-343.

43. Crabtree BF, Miller WL, eds. Doing Qualitative Research. 2nd ed. Thousand Oaks, CA: Sage Publication; 1999.

44. Miller WL, Crabtree BF. The dance of interpretation. In: Crabtree BF, Miller WL, eds. Doing Qualitative Research. 2nd ed. Thousand Oaks, CA: Sage Publications, Inc; 1999:127-143.
45. Borkan J. Immersion/crystallization. In: Crabtree BF, Miller WL, eds. Doing Qualitative Research. 2nd ed. Thousand Oaks, CA: Sage Publications, Inc: 1999:179-194.

46. Krist AH, Woolf SH, Frazier CO, et al. An electronic linkage system for health behavior counseling effect on delivery of the 5A's. Am J Prev Med. 2008;35(5 Suppl):S350-S358.

47. McKee MD, Maher S, Deen D, Blank AE. Counseling to prevent obesity among preschool children: acceptability of a pilot urban primary care intervention. Ann Fam Med. 2010;8(3):249-255.

48. Fernald DH, Dickinson ML, Froshaug DB, et al. Health behavior changes in multiple interventions in primary care: Results of the Prescription for Health COMBO Study. Am J Prev Med. In press.

49. Cohen DJ, Crabtree BF, Etz RS, et al. Fidelity versus flexibility: translating evidence-based research into practice. Am J Prev Med. 2008;35(5)(Suppl):S381-S389.

\section{Get the Annals by} e-Mail

Make sure you see every new issue

while it's fresh; have the table of

contents sent to you by e-mail for

easy access to articles of interest.

Don't miss important research.

Request the e-mail table of contents at http://lyris.aafp.org/subscribe/annals/.

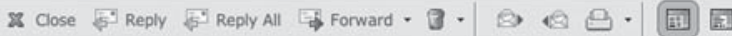 Mail Properties Personalize Message Source}

From: "Annals of Family Medicine" <annalstocelyris.aafp.org> Subject: Annals of Family Medicine Table of Contents

\section{FAMILY MEDICINE}

Indered in tho MEDLINE and MEDLARS
databases

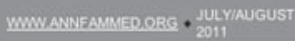

ANNOUNCEMENT

The Annals' 2010 impact factor is 4.45 .

The full text of the journal is available online at nttpy /hwww annfammed org and through various aggregators, including PubMed Central, EBSCO, and MDConsult. The Anna/s is indexed in the
MEDLIINE and MEDLARS, Science Citation Index Expanded, Current Contents/Clinical Medicine. PSycINFO, EMBASE, and CINHAL databases.

\section{EDITORIALS}

In This lssue: Technology and Primary Care

Robin S. Gover

Barbara Starfeld: Passage of the Pathinder of Primary Care

The Potential of Sensor-Based Monitoring, as a Tool for Health Care. Health Promotion, and Research Kevin G. Stanler Nathaniel D. Osgood

\section{DRIGINAL RESEARCH}

Consumption of Tea and Coffee and MRSA Nasal Carriage

(is assciated with a decreased likelihood of MRSA nasa carriage.

Severity of Depression and Magnitude of Productivity LosS Ame Beck; A. Lauren Crain; Leifl. Solberg: Jürgen Unüzer, Russell E. Glasgow: Michael V. 